\title{
Impact of Gut Bacteria on the Infection and Transmission of Pathogenic Arboviruses by Biting Midges and Mosquitoes
}

\author{
Tim W. R. Möhlmann ${ }^{1} \cdot$ Chantal B. F. Vogels ${ }^{1,2} \cdot$ Giel P. Göertz $^{3} \cdot$ Gorben P. Pijlman $^{3}$ • Cajo J. F. ter Braak ${ }^{4}$. \\ Dennis E. te Beest ${ }^{4}$ - Marc Hendriks ${ }^{5}$. Els H. Nijhuis ${ }^{5}$. Sven Warris ${ }^{6}$ - Barbara S. Drolet ${ }^{7} \cdot$ Leo van Overbeek $^{5}$. \\ Constantianus J. M. Koenraadt ${ }^{1}$ (D)
}

Received: 23 October 2019 / Accepted: 23 April 2020 / Published online: 27 May 2020

(C) The Author(s) 2020

\begin{abstract}
Tripartite interactions among insect vectors, midgut bacteria, and viruses may determine the ability of insects to transmit pathogenic arboviruses. Here, we investigated the impact of gut bacteria on the susceptibility of Culicoides nubeculosus and Culicoides sonorensis biting midges for Schmallenberg virus, and of Aedes aegypti mosquitoes for Zika and chikungunya viruses. Gut bacteria were manipulated by treating the adult insects with antibiotics. The gut bacterial communities were investigated using Illumina MiSeq sequencing of 16S rRNA, and susceptibility to arbovirus infection was tested by feeding insects with an infectious blood meal. Antibiotic treatment led to changes in gut bacteria for all insects. Interestingly, the gut bacterial composition of untreated $A e$. aegypti and C. nubeculosus showed Asaia as the dominant genus, which was drastically reduced after antibiotic treatment. Furthermore, antibiotic treatment resulted in relatively more Delftia bacteria in both biting midge species, but not in mosquitoes. Antibiotic treatment and subsequent changes in gut bacterial communities were associated with a significant, 1.8-fold increased infection rate of $C$. nubeculosus with Schmallenberg virus, but not for $C$. sonorensis. We did not find any changes in infection rates for Ae. aegypti mosquitoes with Zika or chikungunya virus. We conclude that resident gut bacteria may dampen arbovirus transmission in biting midges, but not so in mosquitoes. Use of antimicrobial compounds at livestock farms might therefore have an unexpected contradictory effect on the health of animals, by increasing the transmission of viral pathogens by biting midges.
\end{abstract}

Keywords Arbovirus $\cdot$ Transmission $\cdot$ Microbiome $\cdot$ Biting midge $\cdot$ Mosquito

\section{Introduction}

Symbiotic microorganisms play a key role in the physiology of their insect hosts $[1,2]$. For example, microorganisms that

Tim W. R. Möhlmann and Chantal B. F. Vogels contributed equally to this work.

Electronic supplementary material The online version of this article (https://doi.org/10.1007/s00248-020-01517-6) contains supplementary material, which is available to authorized users.

Constantianus J. M. Koenraadt

sander.koenraadt@wur.nl

1 Laboratory of Entomology, Wageningen University \& Research, P.O. Box 16, 6700 AA Wageningen, The Netherlands

2 Department of Epidemiology of Microbial Diseases, Yale School of Public Health, 60 College Street, New Haven, CT 06510, USA

3 Laboratory of Virology, Wageningen University \& Research, P.O. Box 16, 6700, AA Wageningen, The Netherlands reside in the insect gut provide extra nutrients to insects with a poor diet, such as aphids and termites [3, 4]. Furthermore, gut bacteria are important in insect development and fitness. Developmental time was delayed and egg production was
4 Biometris, Wageningen University \& Research, P.O. Box 16, 6700, AA Wageningen, The Netherlands

5 Biointeractions and Plant Health, Wageningen University \& Research, P.O. Box 16, 6700, AA Wageningen, The Netherlands

6 Bioscience, Wageningen University \& Research, P.O. Box 16, 6700, AA Wageningen, The Netherlands

7 Arthropod-Borne Animal Diseases Research Unit, USDA, Agricultural Research Service, 1515 College Ave, Manhattan, KS, USA 
reduced in mosquitoes reared free of living bacteria $[5,6]$. Of particular interest is the tripartite interaction among the insect vector, their midgut bacteria, and the pathogens that these vectors may transmit $[7,8]$. Midgut microbiota can provide direct protection against pathogens that enter the insect body as was shown for Triatomine bugs and malaria mosquitoes [9, 10]. For several arboviruses transmitted by Aedes aegypti, there is evidence for both positive and negative effects [11-14]. The beneficial bacteria have already been used in the control of arthropod-borne pathogens. Genetically modified bacterial symbionts such as Asaia, Pantoea agglomerans, Rhodococcus rhodnii, and Serratia have been used to combat pathogen transmission by vectors [12, 15-20]. In addition, the endosymbiotic bacterium Wolbachia is a well-studied example of how a microbe can disrupt the transmission of arboviruses by mosquitoes [21-24]. However, a study conducted on the interaction of Wolbachia and West Nile Virus in Culex mosquitoes showed increased virus titers in the presence of Wolbachia [25]. This indicates that the impact of bacteria on virus transmission is context-dependent.

Although the effects of Wolbachia and several genetically modified bacteria on arbovirus transmission have been extensively studied [11, 21, 24], thus far, only few studies have investigated the role of symbiotic midgut bacteria on pathogen transmission [19]. Pathogens are ingested together with a blood meal and have to overcome the midgut barrier before they can infect the insect body. It is hypothesized that midgut bacteria have an effect on pathogen infection either mechanically or via activation of the vector's immune system. While the interaction of mosquito midgut bacteria with malaria parasites has been studied in more detail [14, 16, 26-29], relatively few studies have investigated the role of microbiota in transmission of arboviruses. Previous reports have shown an increased replication of arboviruses after elimination of the midgut bacteria [12-14, 30-32]. At the individual level, elimination of the mosquito midgut bacteria seems to reduce basal levels of antiviral immune response pathways such as the Toll pathway [30], leading to increased susceptibility to arbovirus infection. Although these studies show increased viral titers and reduced immune response pathways, they did not report on infection rate or transmission efficiency, which are important (quantitative) components of vector competence. Knowledge on the impact of the midgut bacterial community on the proportion of vectors that can transmit an arbovirus (vector competence) is currently lacking.

The aim of this study was to investigate the effect of gut bacteria on infection and transmission of arboviruses by their vector. As a model system, we selected three arboviruses belonging to different families, namely Schmallenberg virus (SBV; family Peribunyaviridae, genus Orthobunyavirus), Zika virus (ZIKV; family Flaviviridae, genus Flavivirus), and chikungunya virus (CHIKV; family Togaviridae, genus Alphavirus). Infection with SBV can result in symptoms ranging from short fevers and diarrhea to severe clinical manifestations, such as congenital malformation in ruminants. Infections with ZIKV and CHIKV can cause mild (fever, arthralgia) to severe disease (microcephaly) in humans. In the model systems, the arboviruses are transmitted by biting midges (SBV by Culicoides nubeculosus and C. sonorensis), or mosquitoes (ZIKV and CHIKV by Aedes aegypti). We sequenced the bacterial content in the gut system of both untreated and antibiotic-treated adult females of the three vector species, to identify changes in the microbial community. Subsequently, we determined infection rates and transmission efficiencies of untreated and antibiotic-treated virus-exposed females. In addition, virus titers were compared between the two treatments to investigate the effect of the gut microbial communities on the replicative fitness of the viruses.

\section{Methods}

To investigate the role of insect midgut bacterial communities on arbovirus infection and transmission, we selected three vector species and three viruses (Fig. 1). The microbial gut communities of antibiotic-treated and untreated adult females were identified and their susceptibility to the respective viruses was tested. Two biting midge species (C. nubeculosus and C. sonorensis) were exposed to SBV. One mosquito species (Ae. aegypti) was exposed to ZIKV or CHIKV. Adult female insects of each species were divided into untreated (control) and antibiotic-treated groups.

\section{Insect Vectors}

Culicoides nubeculosus were provided by The Pirbright Institute, Pirbright Laboratories, UK [33], and were maintained at $23 \pm 1{ }^{\circ} \mathrm{C}$ with $16: 8$ light:dark cycle and $60 \%$ relative humidity. Culicoides sonorensis were provided by the Arthropod-Borne Animal Diseases Research Unit, USDAARS and were maintained at $25^{\circ} \mathrm{C}$ with $16: 8$ light:dark cycle and $70 \%$ relative humidity. Similar rearing protocols were used for both biting midge species [34]. Briefly, eggs were transferred to trays with filter wool pasted to the bottom (Europet Bernina International, Gemert-Bakel, The Netherlands), filled with tap water and two drops of Liquifry No.1 (Interpet, Dorking, UK). Larvae were fed with a 1:1:1 mixture of bovine liver powder (MP biomedicals, Irvine, CA, USA), ground rabbit food (Pets Place, Ede, The Netherlands), and ground koi food (Tetra, Melle, Germany). Culicoides nubeculosus larvae were additionally fed with nutrient broth No. 1 (Oxoid, Hampshire, UK). Pupae were transferred to moist emergence cups that were placed in plastic buckets (diameter $12.2 \mathrm{~cm}$, height $12.2 \mathrm{~cm}$; Jokey, Wipperfürth, Germany) and closed with netting on the 
Fig. 1 Overview of experimental design. Schmallenberg virus was used for infection of Culicoides nubeculosus and C. sonorensis biting midges, whereas Zika and chikungunya viruses were used for infection of Aedes aegypti mosquitoes. All three vector species were divided in an untreated and an antibiotic-treated group. The gut bacterial communities of the three vector species for the untreated and antibiotictreated groups were identified via 16S rRNA sequencing

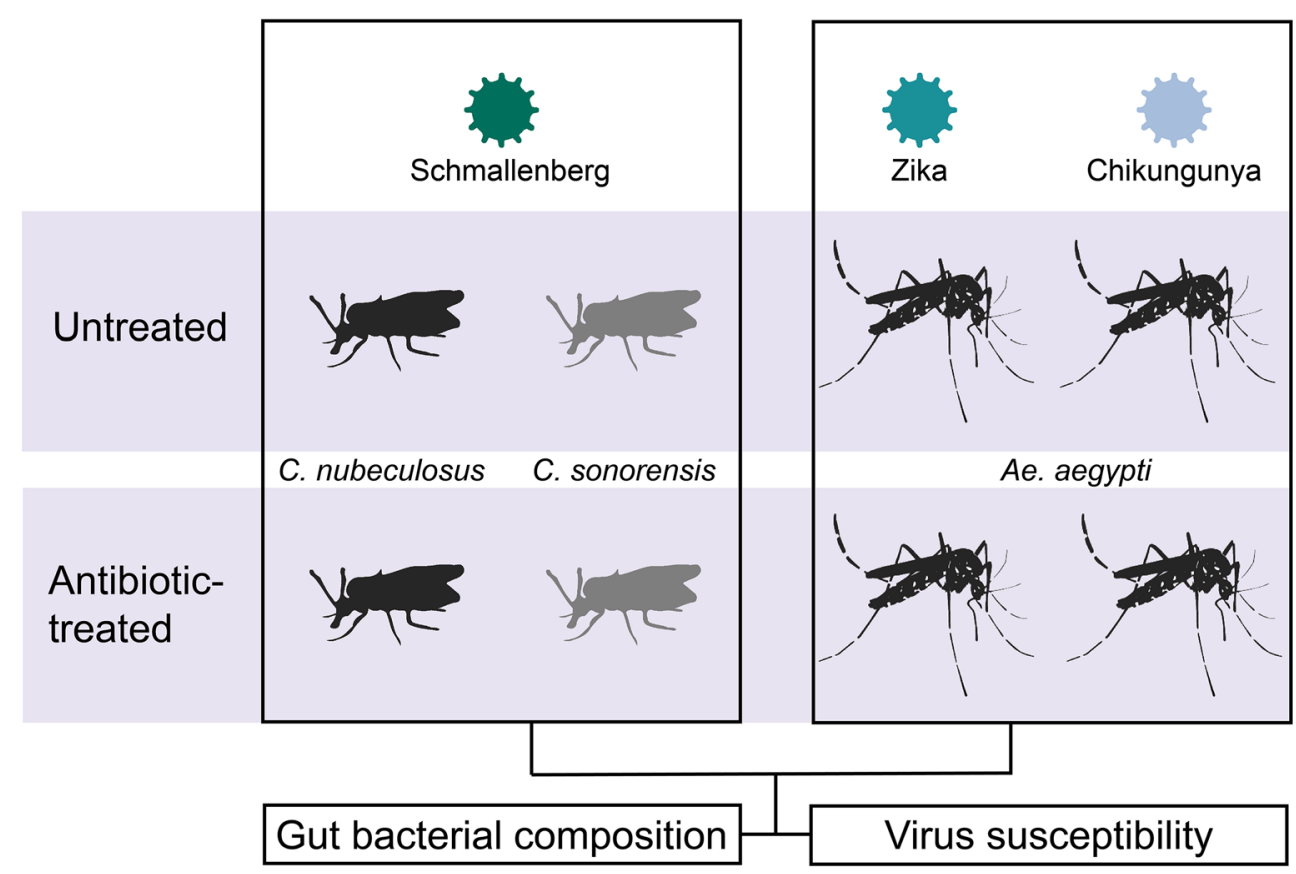

top through which the biting midges could feed. Emerged adults were provided with $6 \%$ glucose solution ad libitum. Antibiotic free, bovine blood (Carus, Wageningen, The Netherlands) was provided through a Parafilm M membrane using the Hemotek PS5 feeding system (Discovery Workshops, Lancashire, UK) for egg production.

Aedes aegypti from the Rockefeller strain (Bayer AG, Monheim, Germany) were used in all mosquito experiments. The mosquito colony was maintained as described previously [35]. In short, mosquitoes were kept at $27 \pm 1{ }^{\circ} \mathrm{C}$ with 12:12 light:dark cycle and $70 \%$ relative humidity. Adult mosquitoes were maintained on $6 \%$ glucose solution ad libitum. Antibiotic free, human blood (Sanquin Blood Supply Foundation, Nijmegen, The Netherlands) was provided through a Parafilm M membrane using the Hemotek PS5 feeding system for egg production. Drought-conditioned eggs were transferred to transparent square larval holding trays $(19 \times 19 \times 20 \mathrm{~cm}$; Jokey), filled for approximately one-third with tap water and three drops of Liquifry No. 1. Hatched larvae were fed with TetraMin Baby fish food (Tetra). Larval trays were closed with fine-meshed netting to allow adult mosquitoes to emerge inside larval trays. Twice a week, adults were aspirated from larval trays and collected in Bugdorm-1 insect rearing cages $(30 \mathrm{~cm} \times 30 \mathrm{~cm} \times 30 \mathrm{~cm}$; BugDorm, Taiwan, China).

\section{Antibiotic Treatment}

Approximately 100-200 C. nubeculosus and C. sonorensis pupae were collected during three consecutive days and placed in a Petri dish containing moistened cotton wool and filter paper in separate buckets (diameter $12.2 \mathrm{~cm}$, height 12.2 $\mathrm{cm}$; Jokey). For a period of 6 days, they were allowed to emerge and had direct access to $6 \%$ glucose solution (untreated group), or $6 \%$ glucose solution containing a combination of $10 \mu \mathrm{g} / \mathrm{ml}$ penicillin and $10 \mu \mathrm{g} / \mathrm{ml}$ streptomycin (Duchefa Biochemie B.V., Haarlem, The Netherlands) (antibiotictreated group) [36]. Penicillin was chosen because it is a broad-spectrum antibiotic against gram-positive bacteria, and streptomycin was chosen because it is a broad-spectrum antibiotic against gram-negative bacteria. Biting midges in the antibiotic-treated group were allowed to feed on a glucose solution with antibiotics for 3 to 6 days before being transferred to the Biological Safety Level 3 (BSL3) facility at Wageningen University \& Research, where arbovirus infections were performed. Antibiotic treatment was continued throughout the duration of the experiments.

Aedes aegypti adults were collected from larval trays and divided into two groups of approximately 100-200 mosquitoes in Bugdorm-1 cages. One cage was maintained on $6 \%$ glucose solution (untreated group), whereas the other cage was maintained on $6 \%$ glucose solution with $20 \mathrm{U} / \mathrm{ml}$ penicillin (SigmaAldrich, Saint Louis, MO, USA) and $20 \mu \mathrm{g} / \mathrm{ml}$ streptomycin (PenStrep) (antibiotic-treated group; Sigma-Aldrich) for 4 days [32]. Females were then transferred to plastic buckets (diameter $12.2 \mathrm{~cm}$, height $12.2 \mathrm{~cm}$; Jokey) and transported to the BSL3 facility for arbovirus infection studies.

\section{Taxonomical Identification of Gut Bacterial Populations}

\section{Sample Preparation}

To gain insight in the effect of the antibiotic treatment on gut bacterial community composition, biting midges and 
mosquitoes were dissected and their gut bacterial communities were identified. Prior to dissection, biting midges were anesthetized by freezing for 15 to $30 \mathrm{~min}$ at $-20{ }^{\circ} \mathrm{C}$. To remove external bacterial contamination, each biting midge was dipped in $70 \%$ ethanol for $10 \mathrm{~s}$, in $5 \%$ sodium hypochlorite solution for $60 \mathrm{~s}$, and finally rinsed in $70 \%$ ethanol for $30 \mathrm{~s}$ [37-39]. After cleaning, pools were made under aseptic conditions from dissected abdomens from five untreated or five antibiotic-treated females in a 2-ml screw cap micro-tube (Sarstedt) with a 4-mm borosilicate glass bead (SigmaAldrich). In total, 18 replicate pools were prepared for untreated and antibiotic-treated C. nubeculosus, and 10 replicate pools for untreated and antibiotic-treated C. sonorensis, resulting in a total of 56 pools.

Similar to the biting midges, mosquito midgut bacteria were investigated. Mosquitoes were treated in a similar manner as described above. Midguts were dissected and pooled from five untreated and five antibiotic-treated females, under aseptic conditions. Selected mosquitoes were anesthetized on ice, dipped in $70 \%$ ethanol for $10 \mathrm{~s}$, and then rinsed in phosphate buffered saline (PBS) for $10 \mathrm{~s}$. Midguts were dissected in a droplet of PBS using forceps, under the dissecting microscope. Five midguts per treatment were pooled in a 2-ml screw cap micro-tube with a 4-mm borosilicate glass bead. In total, 12 replicate pools were prepared for untreated and antibiotictreated Ae. aegypti females, resulting in a total number of 24 pools.

\section{DNA Extraction Protocol}

Midgut pools were placed in Precellys Evolution tissue homogenizer (Bertin Instruments, Montigny-le-Bretonneux, France) and homogenized twice at $7800 \mathrm{rpm}$ for $15 \mathrm{~s}$. The Mag-Bind Tissue DNA KF 96 Kit (Omega Bio-tek, Norcross, GA, USA) was used for DNA extraction of bacterial populations as per the manufacturer's protocol.

\section{qPCR}

Midgut bacterial loads were quantified for each sample by SYBR Green real-time PCR (Thermo Fisher Scientific, Waltham, USA) to estimate the relative abundance of major taxonomic groups of bacteria [40]. For each sample, $5 \mu \mathrm{l}$ was added to a master mix of $20 \mu \mathrm{l}$ consisting of $0.12 \mu \mathrm{l} 100 \mu \mathrm{M}$ Eub338f forward primer, $0.12 \mu \mathrm{l} 100 \mu \mathrm{M}$ Eub518r $\mu$ l reverse primer, $10 \mu \mathrm{l}$ Takara $2 \times, 0.4 \mu \mathrm{l}$ ROX2, and $4.36 \mu 1$ Milli-Q water. The qPCR program was run at $50{ }^{\circ} \mathrm{C}$ for $2 \mathrm{~min}, 95^{\circ} \mathrm{C}$ for $10 \mathrm{~min}$, then 40 cycles of $95{ }^{\circ} \mathrm{C}$ for $15 \mathrm{~s}$ and $50{ }^{\circ} \mathrm{C}$ for 1 min, followed by a final melting and annealing step of $95^{\circ} \mathrm{C}$ for $30 \mathrm{~s}$ and finally $50{ }^{\circ} \mathrm{C}$ for $15 \mathrm{~s}$. Then, these qPCR amplicons were run on gel and the intensity of electrophoresis was used to visually estimate if bacterial DNA load after PCR was comparable among samples. If this was not the case, this process was repeated with adjusted numbers of PCR cycles until comparable DNA load was achieved. Midge DNA extracts were then subjected in triplicate to PCR with $5 \mu$ l sample and $20 \mu \mathrm{l}$ master mixture consisting of $1.2 \mu \mathrm{l}$ dNTP (5 $\mathrm{mM}), 6 \mu \mathrm{l} 5 \mathrm{xQ} 5$ reaction buffer, $0.15 \mu \mathrm{l} 16 \mathrm{~S}$ V4 $515 \mathrm{~F}$ forward primer $(100 \mu \mathrm{M}), 0.15 \mu \mathrm{l}$ 16S V4 806R reverse primer $(100 \mu \mathrm{M}), 0.3 \mu \mathrm{l}$ Q5 HF DNA polymerase, and $14.7 \mu \mathrm{l}$ Milli$\mathrm{Q}$ water [41]. Samples were run on Verity PCR machines (Thermo Fisher Scientific, Waltham, USA) with the following program: $98^{\circ} \mathrm{C}$ for $30 \mathrm{~s}, 98^{\circ} \mathrm{C}$ for $10 \mathrm{~s}, 50^{\circ} \mathrm{C}$ for $30 \mathrm{~s}, 72^{\circ} \mathrm{C}$ for $30 \mathrm{~s}, 72{ }^{\circ} \mathrm{C}$ for $2 \mathrm{~min}$, and $4{ }^{\circ} \mathrm{C}$ until the program was stopped. The number of cycles varied per sample but all were between 16 and 29 cycles. Obtained amplicons of the three PCR replicates per sample were pooled and stored at $-20^{\circ} \mathrm{C}$ before further processing.

\section{Sequencing and Preparation of Data}

Samples were sequenced on an Illumina MiSeq platform (Next Generation Sequencing Facilities, Wageningen University \& Research, Wageningen, The Netherlands). Resulting reads were analyzed with QIIME2 (version 2018.8; https://qiime2.org; [42, 43]). All forward and reverse reads were demultiplexed and linked to sample IDs. Sequence run specific quality control, merging of forward and reverse reads, removal of $16 \mathrm{~S} \mathrm{V4}$ primer sequences and of chimeric sequences was performed with the DADA2 package as QIIME2 plugin [44]. DADA2 grouped unique sequences equivalent to operational taxonomic unit (OTU) clustering at $100 \%$ similarity, resulting in an abundance table (feature table) of the amplicon sequence variants (ASVs) and a file with the unique sequences (rep-seqs). Advantages of the new ASV approach compared with OTU clustering at $97 \%$ similarity have been discussed previously [45]. At first, sequences were aligned with MAFFT plugin [46] and highly variable positions in alignment were masked [47] to reduce noise in the phylogenetic tree. FastTree plugin [48] was used to create an unrooted tree of the unique sequences. The tree was rooted at midpoint of the longest tip-to-tip distance.

Taxonomy was assigned with confidence threshold 0.8 to the unique sequences with Naive Bayes classifier pre-trained on the Silva database release "132 16S V4 region," with QIIME2 classifier plugin (https://docs.qiime2.org/; [49-51]. The ASV abundance table was additionally filtered before further analyses. All sequences were removed that were not classified (unassigned at Kingdom taxa level) or classified as Eukaryotes, plant mitochondria, or chloroplasts, as well as all ASVs without any phylum classification. Very low abundant ASVs with a total count below 10 were also removed as an additional noise reduction before further analyses. For analyses performed in R, the QIIME2 data was extracted into abundance or feature tables and converted from BIOM HDF5 to JSON format [52]. 


\section{Negative Control Samples}

Negative control samples $(N=14)$ were included that followed the complete protocol from DNA extraction to sequencing. These samples contained no insect material but did generate bacterial sequences. Such contaminants can originate from reagents used in the DNA extraction, PCR, or nextgeneration sequencing library preparation, as well as from human skin, oral, or respiratory microbiota [53, 54]. The 14 samples contained 907 ASVs with a count of 204,153. After filtering of low abundant ASVs, a total of 81 ASVs with a count of 176,725 remained. To identify true contaminants, an occurrence threshold of $20 \%$ was used which means that an ASV was present in at least 3 out of the 14 negative control samples. In addition, the selected contaminants together had to contribute $99 \%$ to the total fraction counts. A total of 51 ASVs with a count of 140,573 were recognized as true contaminations and filtered from the complete dataset before further analyses. Identified contaminants consisted of several common skin bacteria such as Corynebacteria, Propionibacteria, Staphylococci, and Micrococcus [55]. Together, these skinassociated ASVs comprised $20 \%(28,562 / 140,573)$ of the total count in the negative controls (Additional File S2).

\section{Viruses}

SBV was obtained from Wageningen Bioveterinary Research (Lelystad, The Netherlands) as passage three (P3) bovine isolate (B-SBV). Two additional passages, $\mathrm{P} 4$ and P5, were grown on Aedes albopictus C6/36 cells (ATCC, Manassas, USA, CRL-1660) in Leibovitz-15 (L-15) growth medium (Gibco, Carlsbad, CA, USA) supplemented with $10 \%$ fetal bovine serum (FBS), 2\% tryptose phosphate broth (Gibco), and $1 \%$ nonessential amino acids (Gibco), at $27{ }^{\circ} \mathrm{C}$. Viruscontaining supernatants were harvested at 5 days postinoculation and stored in aliquots at $-80{ }^{\circ} \mathrm{C}$. The P4 stock titer was determined by endpoint dilution assays (EPDA) on African green monkey kidney Vero E6 cells (ATCC CRL1586). Virus titers were determined using the Reed and Muench algorithm [56].

ZIKV Suriname strain P4 stock, as described previously by Göertz et al. [35], was used to grow a P5 stock on Vero cells and was used in all mosquito infection experiments. Vero cells were cultured in Dulbecco's modified Eagle medium (HEPES-DMEM; Gibco) supplemented with 10\% FBS, at $37{ }^{\circ} \mathrm{C}$, and $5 \% \mathrm{CO}_{2}$. A T75 flask (Greiner Bio-One, Kremsmünster, Austria) pre-seeded with Vero cells was inoculated with ZIKV P4, and incubated for 3 days. Supernatant was harvested and stored in aliquots at $-80{ }^{\circ} \mathrm{C}$. The $\mathrm{P} 5$ stock titer was determined by EPDA, as described above, on Vero cells.

Chikungunya strain 37997 was produced as previously described [35]. A T75 flask pre-seeded with C6/36 cells was inoculated with CHIKV P1 and incubated for 3 days at 28 ${ }^{\circ} \mathrm{C}$. Supernatant was harvested and stored in aliquots at -80 ${ }^{\circ} \mathrm{C}$. The $\mathrm{P} 2$ stock titer was determined by EPDA, as described above, on Vero cells.

\section{Virus Infections}

Untreated and antibiotic-treated female biting midges were allowed to feed on an infectious blood meal containing $\mathrm{SBV}$, whereas female mosquitoes were allowed to feed on an infectious blood meal containing either ZIKV or CHIKV. For each virus, a 1:1 dilution was prepared by adding an equal amount of bovine blood to SBV stock (average titer in blood meal, $2.5 \times 10^{6}$ ), or human blood to either ZIKV stock (titer in blood meal, $4.0 \times 10^{4}$ ) or CHIKV stock (titer in blood meal, $2.5 \times 10^{8}$ ). These virus titers were deliberately selected based on pilot experiments to obtain intermediate infection rates to facilitate observations of both negative and/or positive effects of the midgut bacteria on virus infection rates. Bovine blood was verified for absence of SBV neutralizing antibodies before the experiment started. The infectious blood meal was provided through a Parafilm $\mathrm{M}$ membrane using the Hemotek PS5 feeding system, at $24 \pm 1{ }^{\circ} \mathrm{C}$ and $70 \%$ relative humidity. Biting midges were fed in the dark, whereas mosquitoes were fed under light conditions. After $1 \mathrm{~h}$, biting midges and mosquitoes were anesthetized with $100 \% \mathrm{CO}_{2}$, placed on a $\mathrm{CO}_{2}$-pad (Genesee Scientific, San Diego, USA), and fully engorged females were selected and placed back in the holding bucket. Biting midges were maintained at $25^{\circ} \mathrm{C}$ for 10 days and provided with $6 \%$ glucose solution ad libitum (untreated). Biting midges in the antibiotic-treated group were continuously fed on the glucose solution with PenStrep (antibiotic-treated). Engorged female mosquitoes in both treatments were maintained at $28{ }^{\circ} \mathrm{C}$ for 10 days and were provided with $6 \%$ glucose solution ad libitum.

\section{Infection and Transmission}

Ten days post-feeding, biting midges were anesthetized with $100 \% \mathrm{CO}_{2}$ and maintained on a $\mathrm{CO}_{2}$-pad. Females were individually transferred to a $1.5-\mathrm{ml}$ Safe-Seal micro-tube (Sarstedt, Nümbrecht, Germany) containing $0.5 \mathrm{~mm}$ zirconium beads (Next Advance, Averill Park, NY, USA) and stored at $-80^{\circ} \mathrm{C}$ until further processing. The whole procedure was replicated three times, which resulted in a total number of 196 untreated $\left(N_{1}=79, N_{2}=49, N_{3}=68\right)$ and 275 antibiotictreated $\left(N_{1}=114, N_{2}=92, N_{3}=69\right)$ C. nubeculosus, and 44 untreated $\left(N_{1}=20, N_{2}=10, N_{3}=14\right)$ and 47 antibiotic-treated $\left(N_{1}=19, N_{2}=5, N_{3}=23\right)$ C. sonorensis.

Ten days post-feeding, mosquitoes were anesthetized with $100 \% \mathrm{CO}_{2}$ and maintained on a $\mathrm{CO}_{2}$-pad to remove their legs and wings with forceps. Mosquito saliva was then collected by inserting the proboscis into a $200-\mu$ yellow pipet tip 
(Greiner Bio-One) containing $5 \mu$ of a 1:1 solution of $50 \%$ glucose solution and FBS. After at least $45 \mathrm{~min}$, the mosquito body (head, thorax, and abdomen) was transferred to a $1.5-\mathrm{ml}$ Safe-Seal micro-tube containing 0.5 -mm zirconium beads. The saliva sample was transferred to a $1.5-\mathrm{ml}$ micro-tube (Sarstedt) containing $55 \mu 1$ 4-(2-hydroxyethyl)-1piperazineethanesulfonic acid-buffered DMEM (HEPESDMEM) supplemented with $10 \%$ FBS, penicillin (100 $\mathrm{U} / \mathrm{ml})$, streptomycin $(100 \mu \mathrm{g} / \mathrm{ml})$, fungizone $(50 \mu \mathrm{g} / \mathrm{ml}$; Invitrogen, Carlsbad, USA), and gentamycin $(50 \mu \mathrm{g} / \mathrm{ml}$; Gibco). All samples were stored at $-80{ }^{\circ} \mathrm{C}$ until further processing. This whole procedure was replicated four times for both ZIKV and CHIKV, with $N=25$ mosquito body and saliva samples per replicate for each of the four treatments.

Frozen biting midge and mosquito bodies were homogenized for 2 min at maximum speed in a Bullet Blender Storm (Next advance, Averill Park, NY, USA), centrifuged briefly, and re-suspended in $100 \mu \mathrm{l}$ of fully supplemented HEPESDMEM. Samples were blended again for $2 \mathrm{~min}$ at maximum speed, and centrifuged for $2 \mathrm{~min}$ at $14,500 \mathrm{rpm}$ in an Eppendorf minispin plus (Eppendorf, Hamburg, Germany). Mosquito saliva samples were thawed at room temperature. In total, $30 \mu \mathrm{l}$ of each body or saliva sample was used to inoculate a monolayer of pre-seeded Vero cells in a 96-well plate. On each plate, diluted virus stock or infectious blood mixture was included as positive controls and wells to which no sample was added were included as negative controls. After $2-3 \mathrm{~h}$, the inoculum was removed and replaced by $100 \mu \mathrm{l}$ of fully supplemented HEPES-DMEM. Wells were scored for virus-induced cytopathic effect (CPE) at 3 and 6 days post-inoculation, with full CPE being observed at the latter time point. Virus titers of infected biting midge bodies and of mosquito body and saliva samples were determined by EPDA on Vero E6 cells [35]. If less than three wells in the first row showed CPE, the titer could not be calculated because the sample contained less than $1000 \mathrm{TCID}_{50}$ per ml.

\section{Statistical Analysis}

The difference in bacterial communities between untreated and antibiotic-treated insects (biting midges or mosquitoes) was tested using a permutation test (999 permutations) based on a redundancy analysis (RDA) of taxa on the treatment factor using Canoco 5.11 [57]. All seven taxonomic levels were used simultaneously in these analyses, obtained by summing the ASV counts to the taxon levels kingdom (bacteria and archaea), phylum, class, order, family, genus, and species. In the analysis, the resulting counts were divided by the library size and the resulting fractions were log-transformed after addition of 0.001 , to avoid problems with zero counts. The value 0.001 was chosen as its inverse is close to the smallest library size and gives a reasonably symmetric distribution of residuals. The approach has the advantage of yielding one test of significance instead of several level-specific tests. Selection of differentially expressed taxa was based on the percentage fit due to the treatment factor (in our case antibiotic treatment).

In addition, we conducted a univariate test using the logtransformed fractions per taxon, to identify taxa that were correlated with untreated or antibiotic-treated samples. Univariate $p$ values were calculated with both Welch's twosample $t$ test (two-sided) and its permuted version. The null distribution of the permuted $t$ test was calculated with 9,999 permutations with the function perm.t.test from the R package deducer. Given the correspondence between the $p$ values of these two methods, the false discovery rate (FDR, BenjaminiHochberg correction) was based on the $p$ values of (parametric) Welch's $t$ test. The FDR was calculated across all taxa levels together and per taxon level. Alpha diversity indices were calculated for Shannon-Wiener Diversity $\left(H^{\prime}\right)$, the Inverse Simpson Index (D2 or N2), and the ShannonWiener Evenness index-based $N 1 / N 2$, where $N 1=\exp \left(H^{\prime}\right)$ and $N 2=$ Inverse Simpson Index using the VEGAN version 2.9.2. package [58] in the statistical software package $R$ version 3.5.0 [59].

Chi-square tests were used to test for the effect of antibiotic treatment on infection rate and transmission efficiency. For biting midges, only infection rates were determined, whereas both infection rates and transmission efficiency were determined for mosquitoes. Infection rate and transmission efficiency were calculated, respectively, by dividing the number of female vectors with virus-infected whole body (infection) or virus-infected saliva (transmission) by the total number of alive female vectors tested in the respective treatment, and multiplied by 100 . Mann-Whitney $U$ tests were used to test for the effect of antibiotic treatment on virus titers of body or saliva samples. All statistical analyses were done with the statistical software package R [59].

\section{Results}

\section{Gut Bacterial Communities}

To gain insight in the effect of the antibiotic treatment on the composition of gut bacterial communities, the identities of gut bacteria populations in adult female $C$. nubeculosus, C. sonorensis, and Ae. aegypti were determined by highthroughput $16 \mathrm{~S}$ rRNA gene sequencing before blood-feeding. In addition, to uncover the role that specific gut bacteria may play in virus infection, bacterial species that were significantly different between untreated and antibiotic-treated females were determined by Redundancy analyses (RDA).

The communities of gut bacteria were significantly different between untreated and antibiotic-treated groups for all three vector species $(p<0.01$; Fig. 2a, c, e) The first principal component $(\mathrm{PC})$, reflecting the difference between the 
bacterial communities of untreated and antibiotic-treated mosquitoes or biting midges, could explain a large part of the total variance (Fig. 2a, c, e). There was a significant difference between the gut bacterial communities of untreated and antibiotic-treated for $C$. nubeculosus ( $p=0.001$; Fig. $2 \mathrm{a}$, the first PC explained $49 \%$ of the total variation), C. sonorensis ( $p$ $=0.001$; Fig. $2 \mathrm{c}$, the first PC explained $14 \%$ of the total variation), and Ae. aegypti ( $p=0.001$; Fig. 2e, the first PC explained $22 \%$ of the total variation).
After antibiotic treatment, a clear shift in gut microbial community was observed in C. nubeculosus and Ae. aegypti (Fig. 2b, f). Untreated samples of these two species were dominated by a single ASV that had a relative frequency of 34 to $98 \%$ of the total bacterial community (Fig. 2b, f). This ASV was identified as gram-negative Asaia bacterium (Phylum: Proteobacteria; family: Acetobacteraceae). The gut bacterial community of $C$. nubeculosus and Ae. aegypti that were treated with antibiotics still contained Asaia, but only up
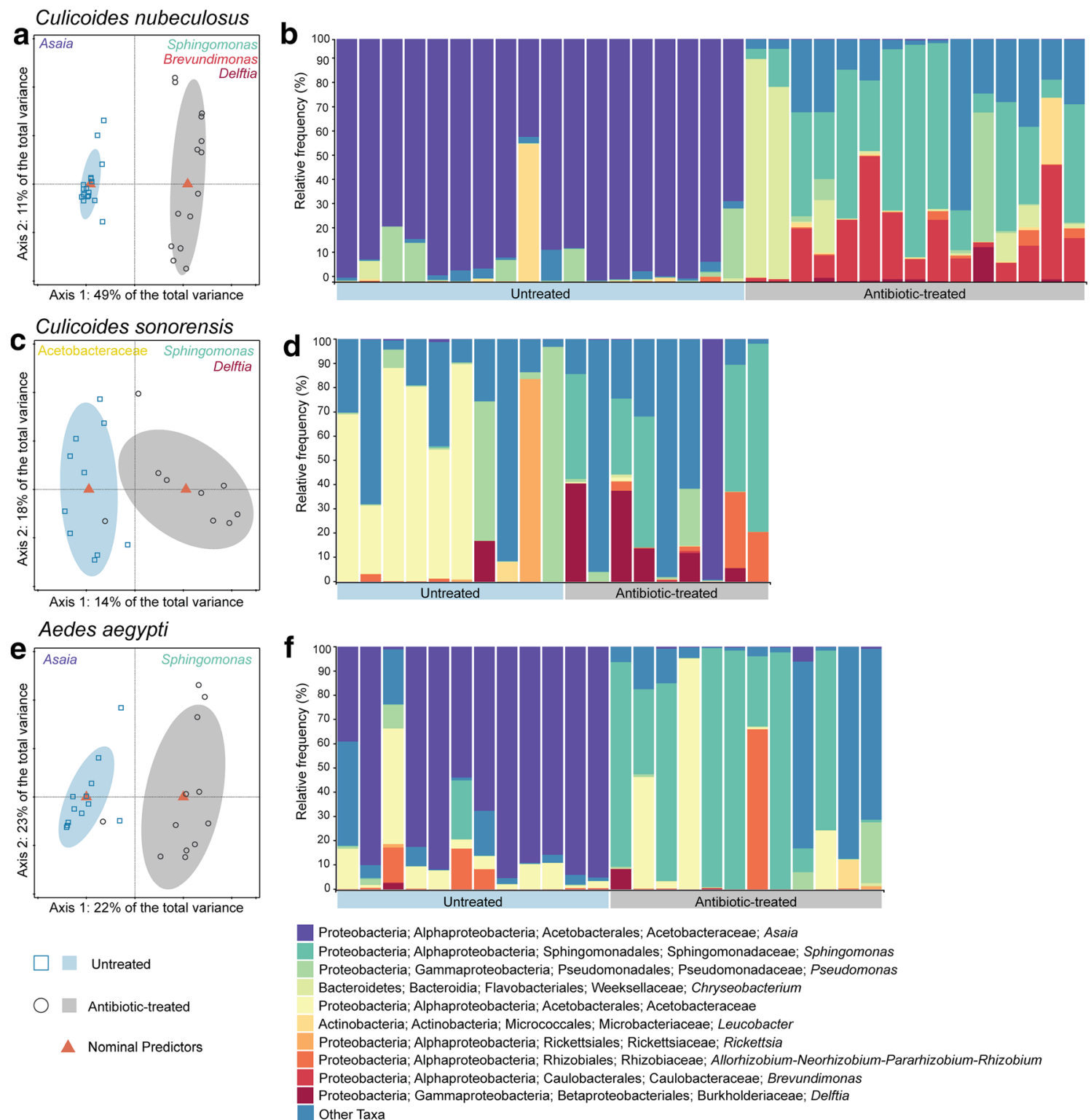

Fig. 2 Overview of bacterial communities in untreated and antibiotictreated biting midges and mosquitoes. RDA of logarithm of the fraction of bacteria in untreated and antibiotic-treated females of Culicoides nubeculosus (panel a; $N=33, D F=1, F=30.0, p=0.001$ ), C. sonorensis (panel c; $N=19, D F=1, F=2.7, p=0.001$ ), and Aedes aegypti (panel e; $N=24, D F=1, F=6.1, p=0.001$ ). Ellipses show $66 \%$ confidence levels ( \pm 1 time the standard deviation). A maximum of three taxa correlated with the untreated or antibiotic-treated groups are named at the top of panels $\mathbf{a}, \mathbf{c}$, and $\mathbf{e}$ for each species. $\mathbf{b}, \mathbf{d}, \mathbf{f}$ Taxa-plots at genus level, on the relative frequency for each taxon, of the total number of midgut bacteria in the community composition are presented. The 10 most abundant bacterial taxa are presented for midgut bacterial communities in $C$. nubeculosus, $C$. sonorensis, and Ae. aegypti. Less abundant taxa were grouped as "Other taxa" to increase visualization for the taxa plots. Each bar represents the relative frequency of bacterial taxa in one pool of five abdomens 
to $3 \%$ of the total bacterial community. A shift in midgut bacterial species was less evident for $C$. sonorensis, which overall showed more variation in bacterial communities in both the untreated and antibiotic-treated groups (Fig. 2d). Interestingly, the diversity of bacteria was higher for all three insect species after antibiotic treatment compared with the untreated group (Table 1).

The family Acetobacteraceae was associated with each untreated group of insects, and more specifically for both C. nubeculosus and Ae. aegypti, the genus Asaia within the Acetobacteraceae family. The antibiotic-treated groups for all three vector species were represented by the presence of bacteria in the Sphingomonas genus when compared with the untreated groups. In addition, Delftia bacteria were correlated with antibiotic-treated biting midges (Fig. 2).

\section{Infection Rates and Transmission Efficiency}

Vector competence was determined for untreated and antibiotic-treated biting midges and mosquitoes to gain insight in the role of midgut bacteria in virus infection and transmission. Infection rates were determined for untreated and antibiotic-treated females of the two biting midge species C. nubeculosus and C. sonorensis. When comparing C. nubeculosus females fed on glucose solution with females fed on glucose solution containing antibiotics, the proportion of SBV-infected females significantly increased from 11.2 to $19.6 \%$ ( $\chi^{2}$ test, $p=0.02$ ). For $C$. sonorensis, infection rates increased from $18.2 \%$ for untreated to $34.0 \%$ for antibiotictreated females ( $\chi^{2}$ test, $p=0.14$; Fig. 3a; Table 2$)$. The observed increase for $C$. sonorensis was not significant, presumably due to the lower number of tested individuals for this species. Although the infection rate was higher in antibiotictreated C. nubeculosus, the median virus titer of SBV-infected biting midges was not significantly different between untreated and antibiotic-treated C. nubeculosus (Mann-Whitney $U$ test, $p=0.42$ ) and $C$. sonorensis (Mann-Whitney $U$ test, $p=$ 0.89 ; Fig. 3b; Table 2).

Table 1 Gut microbial diversity. Estimators of taxonomic diversity for gut microbiota of Aedes aegypti, Culicoides nubeculosus, and C. sonorensis kept on either $6 \%$ glucose solution (untreated) or $6 \%$ glucose solution with penicillin and streptomycin (antibiotic-treated).
$S B V$ Schmallenberg virus, ZIKV Zika virus, CHIKV chikungunya virus. Untreated: fed with $6 \%$ glucose solution; antibiotic: fed with $6 \%$ glucose solution with addition of penicillin and streptomycin; $\mathrm{TCID}_{50} / \mathrm{ml}: 50 \%$ tissue culture infective dose per milliliter

Infection rates and transmission efficiencies were determined for Ae. aegypti females exposed to infectious blood meals containing ZIKV or CHIKV. No significant differences were found in infection rates between untreated and antibiotic-treated $A e$. aegypti females exposed to ZIKV $\left(9.0-12.0 \% ; \chi^{2}\right.$ test, $p=$ $0.64)$ or CHIKV (90.0-95.0\%; $\chi^{2}$ test, $p=0.28$; Fig. 3c; Table 2). Moreover, no differences were found between virus titers of bodies of untreated and antibiotic-treated ZIKV-infected females (Mann-Whitney $U$ test, $p=0.29$ ) or CHIKV-infected females (Mann-Whitney $U$ test, $p=0.84$; Fig. 3d; Table 2).

None of the saliva samples was found positive for ZIKV by $\mathrm{CPE}$; therefore, no transmission was observed for any of the ZIKV-exposed Ae. aegypti females. No significant differences were found in transmission efficiency between untreated and antibiotic-treated Ae. aegypti females exposed to CHIKV ( $\chi^{2}$ test, $p=0.59$; Fig. 3e; Table 2). Moreover, virus titers in saliva samples of CHIKV-infected females were all lower than $10^{3}$ $\mathrm{TCID}_{50} / \mathrm{ml}$ (Fig. 3f; Table 2).

\section{Discussion}

The aim of this study was to investigate whether gut bacteria influence arbovirus infection and transmission in insect vectors. Our data show that feeding C. nubeculosus with antibiotics significantly changed their gut bacterial community composition, which was associated with increased virus susceptibility. Similar treatment had no implications for virus transmission in C. sonorensis or Ae. aegypti mosquitoes.

\section{Gut Bacterial Communities}

Antibiotic treatment significantly changed the composition of gut bacterial communities in all three vector species. Asaia

Average values (minimum-maximum) are presented for Inverse Simpson Index, Shannon-Wiener Diversity, and Shannon-Wiener Evenness

\begin{tabular}{|c|c|c|c|c|c|c|}
\hline \multirow[t]{3}{*}{ Taxonomic diversity } & \multirow{2}{*}{\multicolumn{2}{|c|}{$\frac{\text { Mosquitoes }}{\text { Aedes aegypti }}$}} & \multicolumn{4}{|l|}{ Biting midges } \\
\hline & & & \multicolumn{2}{|c|}{ Culicoides nubeculosus } & \multicolumn{2}{|c|}{ Culicoides sonorensis } \\
\hline & Untreated & Antibiotic-treated & Untreated & Antibiotic-treated & Untreated & Antibiotic-treated \\
\hline No. of samples & 12 & 12 & 18 & 15 & 10 & 9 \\
\hline Inverse Simpson Index & $1.501(1.009-3.063)$ & $3.038(1.031-11.702)$ & $1.257(1.011-2.070)$ & $2.915(1.237-5.901)$ & $2.437(1.074-7.647)$ & $3.135(1.014-8.401)$ \\
\hline Shannon-Wiener diversity & $0.527(0.039-1.720)$ & $1.055(0.114-3.009)$ & $0.351(0.046-0.837)$ & $1.339(0.528-2.150)$ & $1.070(0.202-2.771)$ & $1.265(0.061-3.289)$ \\
\hline Shannon-Wiener evenness & $1.236(1.031-1.823)$ & $1.385(1.087-1.940)$ & $1.158(1.036-1.332)$ & $1.447(1.302-1.730)$ & $1.522(1.139-2.090)$ & $1.468(1.048-3.192)$ \\
\hline
\end{tabular}




\section{Schmallenberg - Whole body}

a

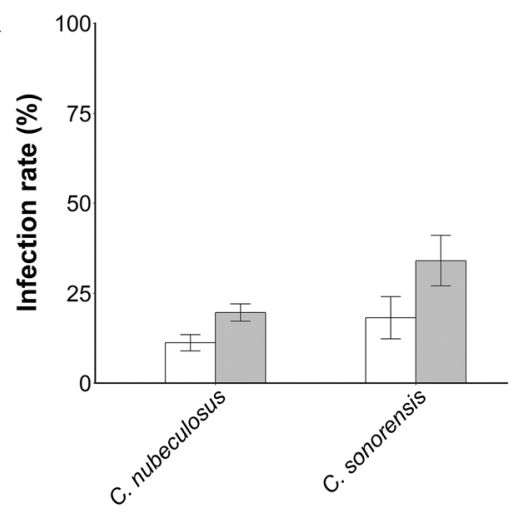

b

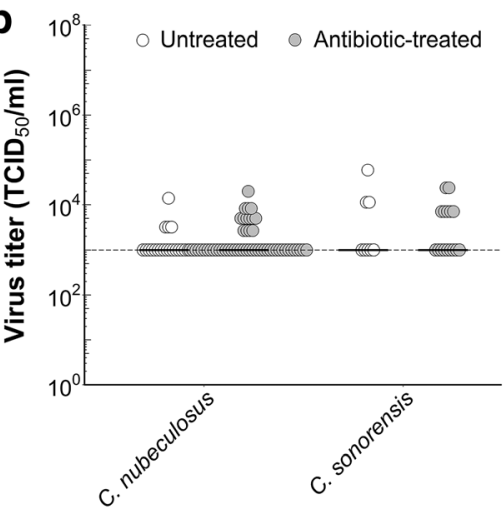

Aedes aegypti - Whole body

C

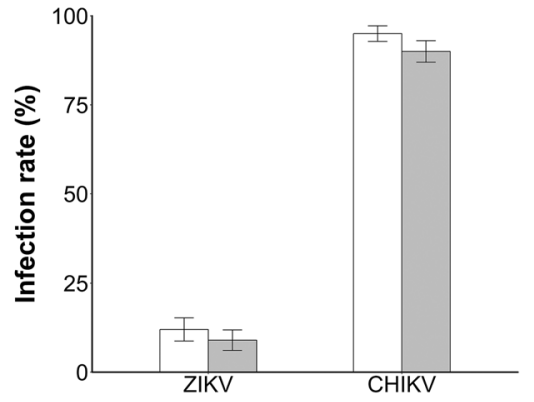

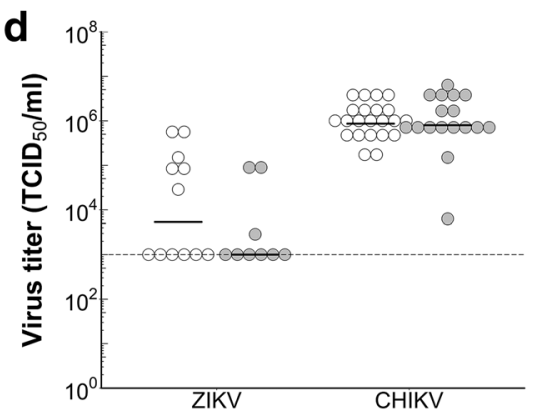

Aedes aegypti - Saliva

e

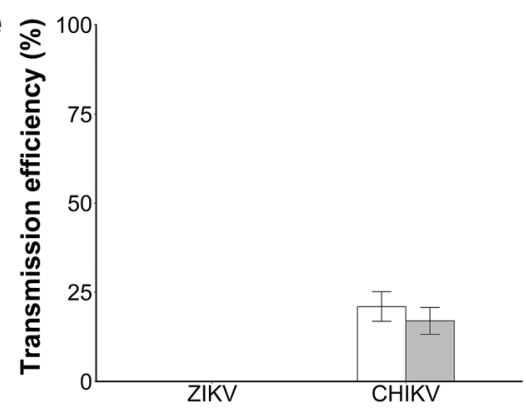

Fig. 3 Effect of antibiotic treatment on susceptibility of biting midges and mosquitoes for arthropod-borne viruses. a Mean infection rates of Schmallenberg virus (SBV) in biting midges $(N$ nubeculosus $=196, N$ sonorensis $=44$; untreated: white bars) fed on glucose solution and glucose solution with antibiotics ( $N \_$nubeculosus $=275, N \_$sonorensis $=47$; antibiotic-treated: gray bars). Culicoides nubeculosus and $C$. sonorensis were blood-fed 3 to 6 days after emergence and tested for virus infection after an incubation period of 10 days. Error bars indicate the SEM. b Average titers of SBV in infected biting midges (C. nubeculosus and C. sonorensis) for both treatments (untreated: white dots and antibiotictreated: gray dots). Each dot represents the titer for one individual biting midge and horizontal bars indicate the median. $\mathbf{c}$ Mean infection rates of Zika virus (ZIKV) and chikungunya virus (CHIKV) in Aedes aegypti mosquitoes ( $N=100$ for each group) fed on glucose solution (untreated: white bars) and glucose solution with antibiotics (antibiotic-treated: gray

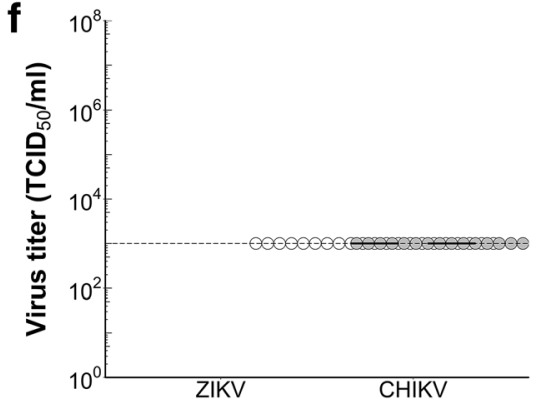

bars). Mosquitoes were blood-fed 4 to 8 days after emergence and tested for virus infection after an incubation period of 10 days. Error bars indicate the SEM. d Average titer of ZIKV and CHIKV in infected mosquitoes for both treatments (untreated: white dots and antibiotic-treated: gray dots). Each dot represents the titer for one individual mosquito and horizontal bars indicate the median. e Percentage positive saliva samples (transmission efficiency) for untreated (white bars) and antibiotictreated (gray bars) Ae. aegypti mosquitoes exposed to ZIKV or CHIKV $(N=100$ for each group). Error bars indicate the SEM. $\mathbf{f}$ Average titer of ZIKV- and CHIKV-positive saliva samples of untreated (white dots) and antibiotic-treated (gray dots) Ae. aegypti mosquitoes. No positive saliva samples were found for ZIKV-infected mosquitoes. Each dot represents the titer for one individual mosquito and horizontal bars indicate the median 
Table 2 Infection rates, transmission efficiencies, and median (ingested) titers of untreated and antibiotic-treated biting midges orally exposed to Schmallenberg virus, and untreated and antibiotic-treated Aedes aegypti mosquitoes orally exposed to Zika virus or chikungunya virus. Infection rates and transmission efficiencies were determined as the percentage of insects with virus in their body or saliva, respectively, out of the total number of orally exposed insects within the respective treatment.
Infection rates and transmission efficiencies are presented as percentages (number of virus positive bodies or saliva samples/total number of engorged females). Titers were determined for infected biting midge bodies, for mosquitoes infected with ZIKV, and for mosquitoes with a fully disseminated infection of CHIKV. The results represent the cumulative data from three (biting midges) or four (mosquitoes) independent biological replicates

\begin{tabular}{|c|c|c|c|c|c|c|c|}
\hline Species & Virus & Treatment & Infection (\%) & $\begin{array}{l}\text { Transmission } \\
(\%)\end{array}$ & $\begin{array}{l}\text { Median ingested virus } \\
\text { titers }\left(\mathrm{TCID}_{50} / \mathrm{ml}\right)\end{array}$ & $\begin{array}{l}\text { Median titer body } \\
\left(\mathrm{TCID}_{50} / \mathrm{ml}\right)\end{array}$ & $\begin{array}{l}\text { Median titer saliva } \\
\left(\text { TCID }_{50} / \mathrm{ml}\right)\end{array}$ \\
\hline \multirow[t]{2}{*}{ Culicoides nubeculosus } & \multirow[t]{4}{*}{ SBV } & Untreated & $11.2(22 / 196)$ & - & - & $1 \times 10^{3}$ & - \\
\hline & & Antibiotic & $19.6(54 / 275)$ & - & - & $1 \times 10^{3}$ & - \\
\hline \multirow[t]{2}{*}{ Culicoides sonorensis } & & Untreated & $18.2(8 / 44)$ & - & - & $1 \times 10^{3}$ & - \\
\hline & & Antibiotic & $34.0(16 / 47)$ & - & - & $1 \times 10^{3}$ & - \\
\hline \multirow[t]{4}{*}{ Aedes aegypti } & \multirow[t]{2}{*}{ ZIKV } & Untreated & $12.0(12 / 100)$ & $0(0 / 100)$ & $1 \times 10^{3}$ & $1.5 \times 10^{4}$ & - \\
\hline & & Antibiotic & $9.0(9 / 100)$ & $0(0 / 100)$ & $1 \times 10^{3}$ & $1 \times 10^{3}$ & - \\
\hline & \multirow[t]{2}{*}{ CHIKV } & Untreated & $95.0(95 / 100)$ & $21(21 / 100)$ & $2 \times 10^{5}$ & $8.7 \times 10^{5}$ & $1 \times 10^{3}$ \\
\hline & & Antibiotic & $90.0(90 / 100)$ & $17(17 / 100)$ & $1.7 \times 10^{5}$ & $8.0 \times 10^{5}$ & $1 \times 10^{3}$ \\
\hline
\end{tabular}

was identified as the most dominant bacterial genus in gut bacterial communities of the untreated groups, whereas this particular bacterium was almost non-existent in the antibiotictreated groups. A relative reduction in Asaia bacteria therefore may be associated with increased infection of $C$. nubeculosus with SBV. Interestingly, similar changes in the relative abundance of Asaia induced by antibiotic treatment in Ae. aegypti did not result in any changes in susceptibility to ZIKV or CHIKV. This suggests that gut bacteria may interact in a specific manner with viruses and their vectors. At this point, we cannot provide conclusive evidence on the effect of Asaia on the infectivity of arboviruses in mosquitoes and biting midges. Therefore, we cannot rule out the effect of bacterial gut community density or of relatively less abundant bacteria on this tripartite interaction. This uncertainty can be illustrated by our findings on gut bacteria of $C$. sonorensis, in which Asaia was not the dominant species although we still found a (nonsignificant) trend towards increased infection in the antibiotic-treated group. Untreated $C$. sonorensis gut bacterial communities were dominated by Pseudomonas, Acetobacteraceae, and Azospirillaceae, whereas after treatment with antibiotics, communities were dominated by Sphingomonas and Delftia. These findings point to a potential role of gut bacteria other than Asaia in interference with virus infection, or possible effects of overall bacterial density. Delftia bacteria were found in antibiotic-treated individuals of both biting midge species, whereas they were not abundant in antibiotic-treated mosquitoes. Re-introduction of specific bacteria such as Asaia or Delftia in axenic and gnotobiotic biting midges and mosquitoes would provide important insights in species-specific roles in virus-vector interactions [5, 6, 19].

Recently, several studies have shown that bacteria in the gut of laboratory-reared mosquitoes and biting midges are different from those found in field populations [60-63]. Therefore, our findings may not directly apply to field populations of mosquitoes and biting midges. While the bacterial communities of laboratory-reared mosquitoes used for this experiment did not show any effect on virus infection or replication, midgut bacterial species found in wild populations may still have an effect. Follow-up studies should focus on identification of bacterial species from field-collected mosquitoes and biting midges, and subsequently test their vector competence.

\section{Virus Susceptibility}

After antibiotic treatment, the susceptibility of C. nubeculosus to SBV increased, with almost twice as many individuals infected compared with the untreated group. For C. sonorensis and Ae. aegypti, infection rates remained equal for SBV, and ZIKV and CHIKV, respectively. Moreover, no differences in virus titers were observed between any of the untreated and antibiotic-treated groups. This suggests that the virus replicative fitness remains similar even though infectivity of SBV in the gut of $C$. nubeculosus biting midges is increased after changes in the gut bacterial communities. Absence of a salivary gland barrier for some arboviruses in Culicoides biting midges [64-66] suggests that higher infection rates could result in increased vector competence. We, therefore, conclude that exposure of emerging biting midges to antibiotics may cause subsequent changes in the gut bacterial communities of biting midges. This could in turn increase the risk for SBV infection of biting midges and subsequent transmission to mammalian hosts.

No effect of antibiotic treatment and consequential changes in the gut bacterial community was found on virus susceptibility or replication for Ae. aegypti mosquitoes in our studies. 
Earlier studies on susceptibility of Ae. aegypti for dengue virus (DENV), La Crosse virus, and CHIKV showed that specific bacteria (i.e., Serratia odorifera and Chromobacterium) could influence virus replicative fitness inside the mosquito [11-14]. For instance, the bacteria Serratia odorifera positively influenced DENV and CHIKV in Ae. aegypti mosquitoes, whereas Chromobacterium reduced the infection of DENV in this mosquito species. In addition, the bacteria Serratia marcescens facilitate DENV-2 infection by cleavage of membrane-bound mucins on the mosquito's midgut epithelial cells [67]. Here, we identified bacteria from the same families (Enterobacteriaceae and Neisseriaceae), but did not identify bacteria classified as Serratia or Chromobacterium. The discussed studies found an effect of specific bacteria on virus infection, whereas we did not observe changes in infection after manipulation of the midgut bacterial communities in mosquitoes. This does not necessarily mean that the results of earlier studies and our study are contradictory, but that interactions are likely vector-, virus-, and bacteria speciesspecific. These results underscore the need to further unravel the complex interactions between midgut bacteria and the infectivity of arboviruses. This will contribute to understanding the possible implications of alterations in midgut bacteria, and how specific bacteria could be used as a novel tool for the control of arboviruses $[19,68]$.

Comparing vector competence of different mosquito or biting midge species, it is evident that some species are better able to transmit viruses than others [34, 69-73]. This variation in vector competence is shaped by specific interactions between virus, vector, and environmental factors [74, 75]. Our findings support the hypothesis that the gut bacterial community composition of the vector can also, at least in part, explain variation in vector competence [76]. Thus, we confirm that midgut bacteria add another level of complexity that should be considered when studying the transmission of arboviruses. Future studies on vector competence of mosquitoes or biting midges should include field-collected individuals, to assess how natural-occurring gut bacteria influence their susceptibility to virus infection.

\section{Possible Mechanisms}

The underlying mechanism of increased susceptibility of Culicoides nubeculosus for SBV after antibiotic treatment remains unknown and will be an important issue for future research. Several possibilities for interaction among midgut bacteria, insect vectors, and pathogens can be considered [7, 8]. First, the presence of (sufficient) bacteria could be a key factor to reduce virus infection. This could either be through activation of the vector's innate immune responses $[26,30,31,77$, $78]$ or by directly blocking pathogen interaction with the vector midgut epithelial cells $[10,79-81]$. Second, specific bacteria may facilitate arbovirus infection by digestion of membrane-bound mucins on midgut epithelial cells [67]. Third, direct competition between bacteria and viruses for resources such as lipids or vitamins could affect vector competence [2]. Finally, bacterial secretion of specific antipathogenic molecules, such as reactive oxygen or secondary metabolites, may kill or interfere with pathogens in the midgut [14, 27-29, 79]. Given that Delftia was present in both antibiotic-treated biting midge species, it would be worth investigating whether they play a role in facilitation of virus infection. Facilitation of infection was shown for Anaplasma bacteria in ticks, where these bacteria enhance cell apoptosis, as well as the production of proteins by the vector that reduce the formation of the peritrophic matrix and biofilms, which in turn resulted in increased infection [82, 83].

As mentioned earlier, our findings point to interactions with midgut bacteria that seem specific for each virus-vector combination. It is therefore expected that bacterial species- or population-specific interactions influence virus infection more than the mere presence of bacteria in the midgut. Bacterial interaction with the vector immune responses or secretion of antipathogenic molecules are likely mechanisms for the observed change in infection rates after alteration of the midgut bacteria. Several papers describe the close interaction between bacteria and the innate immune responses of mosquitoes, for example, the ability of the microbiota to modulate virus infection through stimulation of the Toll or IMD immune pathway, making this a valuable direction for further research [14, 20, 30, 31].

Although changes in infection rates may be explained by the differences in bacterial communities, an effect of the antibiotic itself on virus-vector interactions cannot be excluded. Antibiotic treatment may inhibit formation of a peritrophic matrix around the blood bolus after blood-feeding [81], thereby enhancing the possibility of virus particles to interact with the midgut epithelial cells. Furthermore, it was shown that antibiotics can induce long-lasting damaging effects on muscle structure and mitochondrial metabolism in blow flies [84]. Similar effects on midgut cells may result in a "leaky gut," which is a well-described physiological change in insect vector midgut cells that results in increased virus infection [66, $85,86]$. However, low concentrations used in this study might not be enough to cause physiological damage to insect tissues. The way in which antibiotics play a role in changing infection rates is unclear, but it can be concluded that the uptake of antibiotics by biting midges results in higher infection rates with SBV, either through a direct effect of the antibiotic or through an indirect effect of the antibiotic on microbial communities.

\section{The Use of Antibiotics in the Field}

Although the use of antibiotics in the livestock industry has been reduced in several European countries [87, 88], the global use of antibiotics consistently increased from the year 2000 
to 2015 [89]. Of the antimicrobial compounds used in food production systems, up to $80 \%$ ends up in the environment $[90,91]$. For example, antimicrobial compounds are excreted into the environment by livestock animals via urine or dung, as not all antibiotics are degraded during gut passage. This results in relatively high concentrations of antibiotics in manure [92, 93], and consequently in natural habitats of biting midges and mosquitoes. The use of antibiotics in the livestock industry may, therefore, indirectly affect susceptibility of Culicoides vectors for arboviruses, which may result in higher transmission risk of SBV from livestock to biting midges.

\section{Conclusions}

Antibiotic uptake and subsequent changes in gut microbial communities resulted in an almost twofold higher infection rate of the biting midge species $C$. nubeculosus for SBV, but this was not observed with $C$. sonorensis. Use of antimicrobial compounds at livestock farms might therefore have an unexpected contradictory effect on the health of animals, by increasing the transmission of viral pathogens by biting midges. No effect of antibiotic treatment and subsequent shift in bacterial community composition on vector competence of $A e$. aegypti for ZIKV or CHIKV was detected. We therefore conclude that the effect of midgut bacteria of virus infection is context-dependent and virus-vector specific. Understanding the mechanisms of how (specific) midgut bacteria influence the infectivity of arboviruses in their vectors will contribute to the search for new control strategies for vector-borne diseases.

Acknowledgments We would like to thank Corinne Geertsema for maintenance of cell culture and growing the virus stocks and The Pirbright Institute for kindly providing eggs of $C$. nubeculosus. The insect rearing team from the Laboratory of Entomology is acknowledged for maintaining mosquito colonies. We thank colleagues from Carus for providing cattle blood and Elio Schijlen and Bas te Lintel Hekkert for sequencing samples. We thank Paul Mooijman for help with DNA extractions and the initial analyses of sequence data. Finally, we thank Marcel Dicke for providing comments on an earlier version of this manuscript.

Funding Information The Global One Health strategic program of Wageningen University and Research provided funding for this study. Further support was given by Fonds de Vos for Vector-borne diseases of Wageningen University and Research. CBFV is supported by NWO Rubicon 019.181EN.004.

Data Availability All data generated or analyzed during this study are included in this published article and its supplementary information files. The raw sequence data have been deposited in the NCBI BioProject repository, http://www.ncbi.nlm.nih.gov/bioproject/635089.

\section{Compliance with Ethical Standards}

Competing Interests The authors declare that they have no competing interests.
Disclaimer The funders had no role in study design, data collection and analysis, decision to publish, or preparation of the manuscript.

Open Access This article is licensed under a Creative Commons Attribution 4.0 International License, which permits use, sharing, adaptation, distribution and reproduction in any medium or format, as long as you give appropriate credit to the original author(s) and the source, provide a link to the Creative Commons licence, and indicate if changes were made. The images or other third party material in this article are included in the article's Creative Commons licence, unless indicated otherwise in a credit line to the material. If material is not included in the article's Creative Commons licence and your intended use is not permitted by statutory regulation or exceeds the permitted use, you will need to obtain permission directly from the copyright holder. To view a copy of this licence, visit http://creativecommons.org/licenses/by/4.0/.

\section{References}

1. Crotti E, Damiani C, Pajoro M, Gonella E, Rizzi A, Ricci I, Negri I, Scuppa P, Rossi P, Ballarini P (2009) Asaia, a versatile acetic acid bacterial symbiont, capable of cross colonizing insects of phylogenetically distant genera and orders. Environ Microbiol 11:32523264

2. Jupatanakul N, Sim S, Dimopoulos G (2014) The insect microbiome modulates vector competence for arboviruses. Viruses 6:4294-4313

3. Gündüz EA, Douglas A (2009) Symbiotic bacteria enable insect to use a nutritionally inadequate diet. Proc R Soc Lond B Biol Sci 276: 987-991

4. Brune A (2014) Symbiotic digestion of lignocellulose in termite guts. Nat Rev Microbiol 12:168

5. Correa MA, Matusovsky B, Brackney DE, Steven B (2018) Generation of axenic Aedes aegypti demonstrate live bacteria are not required for mosquito development. Nat Commun 9:4464. https://doi.org/10.1038/s41467-018-07014-2

6. Valzania L, Martinson VG, Harrison RE, Boyd BM, Coon KL, Brown MR, Strand MR (2018) Both living bacteria and eukaryotes in the mosquito gut promote growth of larvae. PLoS Negl Trop Dis 12:e006638

7. Hegde S, Rasgon JL, Hughes GL (2015) The microbiome modulates arbovirus transmission in mosquitoes. Curr Opin Virol 15:97102

8. Cirimotich CM, Ramirez JL, Dimopoulos G (2011) Native microbiota shape insect vector competence for human pathogens. Cell Host Microbe 10:307-310

9. Azambuja P, Feder D, Garcia E (2004) Isolation of Serratia marcescens in the midgut of Rhodnius prolixus: impact on the establishment of the parasite Trypanosoma cruzi in the vector. Exp Parasitol 107:89-96

10. Azambuja P, Garcia ES, Ratcliffe NA (2005) Gut microbiota and parasite transmission by insect vectors. Trends Parasitol 21:568 572

11. Bourtzis K, Dobson SL, Xi Z, Rasgon JL, Calvitti M, Moreira LA, Bossin HC, Moretti R, Baton LA, Hughes GL (2014) Harnessing mosquito-Wolbachia symbiosis for vector and disease control. Acta Trop 132:S150-S163

12. Apte-Deshpande A, Paingankar M, Gokhale MD, Deobagkar DN (2012) Serratia odorifera a midgut inhabitant of Aedes aegypti mosquito enhances its susceptibility to dengue- 2 virus. PLoS One 7:e40401

13. Apte-Deshpande AD, Paingankar MS, Gokhale MD, Deobagkar DN (2014) Serratia odorifera mediated enhancement in 
susceptibility of Aedes aegypti for chikungunya virus. Indian J Med Res 139:762

14. Ramirez JL, Short SM, Bahia AC, Saraiva RG, Dong Y, Kang S, Tripathi A, Mlambo G, Dimopoulos G (2014) Chromobacterium Csp P reduces malaria and dengue infection in vector mosquitoes and has entomopathogenic and in vitro anti-pathogen activities. PLoS Pathog 10:e1004398

15. Favia G, Ricci I, Damiani C, Raddadi N, Crotti E, Marzorati M, Rizzi A, Urso R, Brusetti L, Borin S (2007) Bacteria of the genus Asaia stably associate with Anopheles stephensi, an Asian malarial mosquito vector. PNAS 104:9047-9051

16. Bisi DC, Lampe DJ (2011) Secretion of anti-Plasmodium effector proteins from a natural Pantoea agglomerans isolate by using PelB and HlyA secretion signals. Appl Environ Microbiol 77:4669-4675

17. Wang S, Dos-Santos AL, Huang W, Liu KC, Oshaghi MA, Wei G, Agre P, Jacobs-Lorena M (2017) Driving mosquito refractoriness to Plasmodium falciparum with engineered symbiotic bacteria. Science 357:1399-1402

18. Durvasula RV, Gumbs A, Panackal A, Kruglov O, Aksoy S, Merrifield RB, Richards FF, Beard CB (1997) Prevention of insect-borne disease: an approach using transgenic symbiotic bacteria. PNAS 94:3274-3278

19. Guégan M, Zouache K, Démichel C, Minard G, Potier P, Mavingui P, Moro CV (2018) The mosquito holobiont: fresh insight into mosquito-microbiota interactions. Microbiome 6:49

20. Stathopoulos S, Neafsey DE, Lawniczak MK, Muskavitch MA, Christophides GK (2014) Genetic dissection of Anopheles gambiae gut epithelial responses to Serratia marcescens. PLoS Pathog 10: e1003897

21. Iturbe Ormaetxe I, Walker T, LO'Neill S (2011) Wolbachia and the biological control of mosquito borne disease. EMBO Rep 12: 508518.

22. Amuzu HE, Tsyganov K, Koh C, Herbert RI, Powell DR, McGraw EA (2018) Wolbachia enhances insect specific flavivirus infection in Aedes aegypti mosquitoes. Ecol Evol 8:5441-5454

23. Audsley MD, Yixin HY, McGraw EA (2017) The microbiome composition of Aedes aegypti is not critical for Wolbachia-mediated inhibition of dengue virus. PLoS Negl Trop Dis 11:e0005426

24. Moreira LA, Iturbe-Ormaetxe I, Jeffery JA, Lu G, Pyke AT, Hedges LM, Rocha BC, Hall-Mendelin S, Day A, Riegler M (2009) A Wolbachia symbiont in Aedes aegypti limits infection with dengue, chikungunya, and Plasmodium. Cell 139:1268-1278

25. Dodson BL, Hughes GL, Paul O, Matacchiero AC, Kramer LD, Rasgon JL (2014) Wolbachia enhances West Nile virus (WNV) infection in the mosquito Culex tarsalis. PLoS Negl Trop Dis 8: e2965

26. Dong Y, Manfredini F, Dimopoulos G (2009) Implication of the mosquito midgut microbiota in the defense against malaria parasites. PLoS Pathog 5:e1000423

27. Cirimotich CM, Dong Y, Clayton AM, Sandiford SL, Souza-Neto JA, Mulenga M, Dimopoulos G (2011) Natural microbe-mediated refractoriness to Plasmodium infection in Anopheles gambiae. Science 332:855-858

28. Dennison NJ, Saraiva RG, Cirimotich CM, Mlambo G, Mongodin EF, Dimopoulos G (2016) Functional genomic analyses of Enterobacter, Anopheles and Plasmodium reciprocal interactions that impact vector competence. Malar J 15:425

29. Bahia AC, Dong Y, Blumberg BJ, Mlambo G, Tripathi A, BenMarzouk Hidalgo OJ, Chandra R, Dimopoulos G (2014) Exploring Anopheles gut bacteria for Plasmodium blocking activity. Environ Microbiol 16:2980-2994

30. Xi Z, Ramirez JL, Dimopoulos G (2008) The Aedes aegypti toll pathway controls dengue virus infection. PLoS Pathog 4:e1000098

31. Barletta ABF, Nascimento-Silva MCL, Talyuli OA, Oliveira JHM, Pereira LOR, Oliveira PL, Sorgine MHF (2017) Microbiota activates IMD pathway and limits Sindbis infection in Aedes aegypti. Parasit Vectors 10:103

32. Ramirez JL, Souza-Neto J, Cosme RT, Rovira J, Ortiz A, Pascale JM, Dimopoulos G (2012) Reciprocal tripartite interactions between the Aedes aegypti midgut microbiota, innate immune system and dengue virus influences vector competence. PLoS Negl Trop Dis 6:e1561

33. Boorman J (1974) The maintenance of laboratory colonies of Culicoides variipennis (Coq.), C. nubeculosus (Mg.) and C. riethi Kieff. (Diptera, Ceratopogonidae). Bull Entomol Res 64:371-377

34. Möhlmann TWR, Oymans J, Wichgers Schreur PJ, Koenraadt CJM, Kortekaas J, Vogels CBF (2018) Vector competence of biting midges and mosquitoes for Shuni virus. PLoS Negl Trop Dis 12: e0006993. https://doi.org/10.1371/journal.pntd.0006993

35. Göertz GP, Vogels CBF, Geertsema C, Koenraadt CJM, Pijlman GP (2017) Mosquito co-infection with Zika and chikungunya virus allows simultaneous transmission without affecting vector competence of Aedes aegypti. PLoS Negl Trop Dis 11:e005654

36. Touré AM, Mackey AJ, Wang ZX, Beier JC (2000) Bactericidal effects of sugar-fed antibiotics on resident midgut bacteria of newly emerged anopheline mosquitoes (Diptera: Culicidae). J Med Entomol 37:246-249

37. Nayduch D, Erram D, Lee M, Zurek L, Saski C (2015) Impact of the blood meal on humoral immunity and microbiota in the gut of female Culicoides sonorensis. Vet Ital 51:385-392

38. Osei Poku J, Mbogo C, Palmer W, Jiggins F (2012) Deep sequencing reveals extensive variation in the gut microbiota of wild mosquitoes from Kenya. Mol Ecol 21:5138-5150

39. Gusmão DS, Santos AV, Marini DC, Russo ÉS, Peixoto AMD, Bacci Júnior M, Berbert-Molina MA, Lemos FJA (2007) First isolation of microorganisms from the gut diverticulum of Aedes aegypti (Diptera: Culicidae): new perspectives for an insectbacteria association. Mem Inst Oswaldo Cruz 102:919-924

40. Fierer N, Jackson JA, Vilgalys R, Jackson RB (2005) Assessment of soil microbial community structure by use of taxon-specific quantitative PCR assays. Appl Environ Microbiol 71:4117-4120

41. Caporaso JG, Lauber CL, Walters WA, Berg-Lyons D, Lozupone CA, Turnbaugh PJ, Fierer N, Knight R (2011) Global patterns of 16S rRNA diversity at a depth of millions of sequences per sample. PNAS 108:4516-4522

42. Caporaso JG, Kuczynski J, Stombaugh J, Bittinger K, Bushman FD, Costello EK, Fierer N, Pena AG, Goodrich JK, Gordon JI (2010) QIIME allows analysis of high-throughput community sequencing data. Nat Methods 7:335

43. Bolyen E, Rideout JR, Dillon MR, Bokulich NA, Abnet C, AlGhalith GA, Alexander H, Alm EJ, Arumugam M, Asnicar F (2018) QIIME 2: Reproducible, interactive, scalable, and extensible microbiome data science. PeerJ Preprints.

44. Callahan BJ, McMurdie PJ, Rosen MJ, Han AW, Johnson AJA, Holmes SP (2016) DADA2: high-resolution sample inference from Illumina amplicon data. Nat Methods 13:581

45. Callahan BJ, McMurdie PJ, Holmes SP (2017) Exact sequence variants should replace operational taxonomic units in markergene data analysis. The ISME Journal 11:2639

46. Katoh K, Standley DM (2013) MAFFT multiple sequence alignment software version 7: improvements in performance and usability. Mol Biol Evol 30:772-780

47. Lane D (1991) 16S/23S rRNA sequencing. Nucleic acid techniques in bacterial systematics: 115-175.

48. Price MN, Dehal PS, Arkin AP (2010) FastTree 2-approximately maximum-likelihood trees for large alignments. PLoS One 5:e9490

49. Quast C, Pruesse E, Yilmaz P, Gerken J, Schweer T, Yarza P, Peplies J, Glöckner FO (2012) The SILVA ribosomal RNA gene database project: improved data processing and web-based tools. Nucleic Acids Res 41:D590-D596 
50. Pedregosa F, Varoquaux G, Gramfort A, Michel V, Thirion B, Grisel O, Blondel M, Prettenhofer P, Weiss R, Dubourg V (2011) Scikit-learn: machine learning in Python. J Mach Learn Res 12: 2825-2830

51. Bokulich NA, Kaehler BD, Rideout JR, Dillon M, Bolyen E, Knight R, Huttley GA, Caporaso JG (2018) Optimizing taxonomic classification of marker-gene amplicon sequences with QIIME 2's q2-feature-classifier plugin. Microbiome 6:90

52. McDonald D, Clemente JC, Kuczynski J, Rideout JR, Stombaugh J, Wendel D, Wilke A, Huse S, Hufnagle J, Meyer F (2012) The Biological Observation Matrix (BIOM) format or: how I learned to stop worrying and love the ome-ome. GigaScience 1:7

53. Lazarevic V, Gaïa N, Girard M, Schrenzel J (2016) Decontamination of 16S rRNA gene amplicon sequence datasets based on bacterial load assessment by qPCR. BMC Microbiol 16: 73

54. Knights D, Kuczynski J, Charlson ES, Zaneveld J, Mozer MC, Collman RG, Bushman FD, Knight R, Kelley ST (2011) Bayesian community-wide culture-independent microbial source tracking. Nat Methods 8:761

55. Grice EA, Segre JA (2011) The skin microbiome. Nat Rev Microbiol 9:244

56. Reed LJ, Muench H (1938) A simple method of estimating fifty per cent endpoints. Am J Epidemiol 27:493-497

57. ter Braak CJF, Šmilauer P (2018) Canoco reference manual and user's guide: software for ordination (version 5.10). Microcomputer Power, Ithaca, USA

58. Oksanen J, Kindt R, Legendre P, O'Hara B, Simpson G, Stevens M, Wagner H (2009) Vegan: Community Ecology Package. R package version 2(9):2

59. Core Team R (2017) R: A language and environment for statistical computing. R Foundation for Statistical Computing, Vienna, Austria

60. Dickson LB, Ghozlane A, Volant S, Bouchier C, Ma L, Vega-Rúa A, Dusfour I, Jiolle D, Paupy C, Mayanja MN (2018) Diverse laboratory colonies of Aedes aegypti harbor the same adult midgut bacterial microbiome. Parasit Vectors 11:207

61. Muturi EJ, Ramirez JL, Rooney AP, Kim C-H (2017) Comparative analysis of gut microbiota of mosquito communities in central Illinois. PLoS Negl Trop Dis 11:e0005377

62. Gimonneau G, Tchioffo MT, Abate L, Boissière A, AwonoAmbéné PH, Nsango SE, Christen R, Morlais I (2014) Composition of Anopheles coluzzii and Anopheles gambiae microbiota from larval to adult stages. Infect Genet Evol 28:715-724

63. Díaz Sánchez S, Hernández Jarguín A, Torina A, Fernández de Mera IG, Estrada Peña A, Villar M, La Russa F, Blanda V, Vicente J, Caracappa S (2018) Biotic and abiotic factors shape the microbiota of wild-caught populations of the arbovirus vector Culicoides imicola. Insect Mol Biol

64. Fu H, Leake C, Mertens P, Mellor P (1999) The barriers to bluetongue virus infection, dissemination and transmission in the vector, Culicoides variipennis (Diptera: Ceratopogonidae). Arch Virol 144:747-761

65. Mills MK, Michel K, Pfannenstiel RS, Ruder MG, Veronesi E, Nayduch D (2017) Culicoides-virus interactions: infection barriers and possible factors underlying vector competence. Current Opinion in Insect Science.

66. Mellor P, Boorman J, Baylis M (2000) Culicoides biting midges: their role as arbovirus vectors. Annu Rev Entomol 45:307-340

67. Wu P, Sun P, Nie K, Zhu Y, Shi M, Xiao C, Liu H, Liu Q, Zhao T, Chen X, Zhou H, Wang P, Cheng G (2019) A gut commensal bacterium promotes mosquito permissiveness to arboviruses. Cell Host \& Microbe 25: 101-112. doi: https://doi.org/10.1016/j.chom. 2018.11.004

68. Mancini MV, Spaccapelo R, Damiani C, Accoti A, Tallarita M, Petraglia E, Rossi P, Cappelli A, Capone A, Peruzzi G (2016)
Paratransgenesis to control malaria vectors: a semi-field pilot study. Parasit Vectors 9:140

69. Turell MJ, Dohm DJ, Sardelis MR, O'guinn ML, Andreadis TG, Blow JA (2005) An update on the potential of North American mosquitoes (Diptera: Culicidae) to transmit West Nile virus. J Med Entomol 42:57-62. https://doi.org/10.1093/jmedent/42.1.57

70. Turell MJ, Linthicum KJ, Patrican LA, Davies FG, Kairo A, Bailey CL (2008) Vector competence of selected African mosquito (Diptera: Culicidae) species for Rift Valley fever virus. J Med Entomol 45:102-108

71. Vogels CB, Fros JJ, Göertz GP, Pijlman GP, Koenraadt CJ (2016) Vector competence of northern European Culex pipiens biotypes and hybrids for West Nile virus is differentially affected by temperature. Parasit Vectors:9. https://doi.org/10.1186/s13071-016-16770

72. Paweska J, Venter G, Mellor P (2002) Vector competence of South African Culicoides species for bluetongue virus serotype 1 (BTV 1) with special reference to the effect of temperature on the rate of virus replication in C. imicola and C. bolitinos. Med Vet Entomol 16:10-21

73. Balenghien T, Pagès N, Goffredo $M$, Carpenter $S$, Augot D, Jacquier E, Talavera S, Monaco F, Depaquit J, Grillet C (2014) The emergence of Schmallenberg virus across Culicoides communities and ecosystems in Europe. Prev Vet Med 116:360-369

74. Hardy JL, Houk EJ, Kramer LD, Reeves WC (1983) Intrinsic factors affecting vector competence of mosquitoes for arboviruses. Annu Rev Entomol 28:229-262

75. Kenney JL, Brault AC (2014) The role of environmental, virological and vector interactions in dictating biological transmission of arthropod-borne viruses by mosquitoes. Adv Virus Res. Elsevier, pp. $39-83$

76. Novakova E, Woodhams DC, Rodríguez-Ruano SM, Brucker RM, Leff JW, Maharaj A, Amir A, Knight R, Scott J (2017) Mosquito microbiome dynamics, a background for prevalence and seasonality of West Nile virus. Front Microbiol 8:526

77. Dong Y, Aguilar R, Xi Z, Warr E, Mongin E, Dimopoulos G (2006) Anopheles gambiae immune responses to human and rodent Plasmodium parasite species. PLoS Pathog 2:e52

78. Ryu J-H, Kim S-H, Lee H-Y, Bai JY, Nam Y-D, Bae J-W, Lee DG, Shin SC, Ha E-M, Lee W-J (2008) Innate immune homeostasis by the homeobox gene caudal and commensal-gut mutualism in Drosophila. Science 319:777-782

79. Joyce JD, Nogueira JR, Bales AA, Pittman KE, Anderson JR (2011) Interactions between La Crosse virus and bacteria isolated from the digestive tract of Aedes albopictus (Diptera: Culicidae). J Med Entomol 48:389-394

80. Kumar S, Molina-Cruz A, Gupta L, Rodrigues J, Barillas-Mury C (2010) A peroxidase/dual oxidase system modulates midgut epithelial immunity in Anopheles gambiae. Science 327:1644-1648

81. Rodgers FH, Gendrin M, Wyer CA, Christophides GK (2017) Microbiota-induced peritrophic matrix regulates midgut homeostasis and prevents systemic infection of malaria vector mosquitoes. PLoS Pathog 13:e1006391

82. Abraham NM, Liu L, Jutras BL, Yadav AK, Narasimhan S, Gopalakrishnan V, Ansari JM, Jefferson KK, Cava F, JacobsWagner C (2017) Pathogen-mediated manipulation of arthropod microbiota to promote infection. PNAS 114:E781-E790

83. Cabezas-Cruz A, Alberdi P, Ayllón N, Valdés JJ, Pierce R, Villar M, de la Fuente J (2016) Anaplasma phagocytophilum increases the levels of histone modifying enzymes to inhibit cell apoptosis and facilitate pathogen infection in the tick vector Ixodes scapularis. Epigenetics 11:303-319

84. Renault D, Yousef H, Mohamed AA (2018) The multilevel antibiotic-induced perturbations to biological systems: early-life exposure induces long-lasting damages to muscle structure and mitochondrial metabolism in flies. Environ Pollut 241:821-833 
85. Houk E, Obie F, Hardy J (1979) Peritrophic membrane formation and the midgut barrier to arboviral infection in the mosquito, Culex tarsalis Coquillett (Insecta, Diptera). Acta Trop 36:39-45

86. Weaver SC, Scott TW, Lorenz LH, Repik PM (1991) Detection of eastern equine encephalomyelitis virus deposition in Culiseta melanura following ingestion of radiolabeled virus in blood meals. Am J Trop Med Hyg 44:250-259

87. Speksnijder D, Mevius D, Bruschke C, Wagenaar J (2015) Reduction of veterinary antimicrobial use in the Netherlands. The Dutch success model. Zoonoses Public Health 62:79-87

88. Cogliani C, Goossens H, Greko C (2011) Restricting antimicrobial use in food animals: lessons from Europe. Microbe 6:274

89. Klein EY, Van Boeckel TP, Martinez EM, Pant S, Gandra S, Levin SA, Goossens H, Laxminarayan R (2018) Global increase and geographic convergence in antibiotic consumption between 2000 and 2015. PNAS 201717295
90. Sarmah AK, Meyer MT, Boxall AB (2006) A global perspective on the use, sales, exposure pathways, occurrence, fate and effects of veterinary antibiotics (VAs) in the environment. Chemosphere 65: 725-759

91. Andersson DI, Hughes D (2014) Microbiological effects of sublethal levels of antibiotics. Nat Rev Microbiol 12:465

92. Martínez-Carballo E, González-Barreiro C, Scharf S, Gans O (2007) Environmental monitoring study of selected veterinary antibiotics in animal manure and soils in Austria. Environ Pollut 148: 570-579

93. Christian T, Schneider RJ, Färber HA, Skutlarek D, Meyer MT, Goldbach HE (2003) Determination of antibiotic residues in manure, soil, and surface waters. Acta Hydrochim Hydrobiol 31:3644 